\title{
Nuclear Magnetic Resonance Spectroscopy. Structure and Dynamic Character of Allylic Grignard Reagents *
}

\author{
By George M. Whitesides, J. Eric Nordlander and John D. Roberts
}

Gates and Crellin Laboratories of Chemistry, $\uparrow$ California Institute of Technology, Pasadena, California

Received 1st June, 1962

Studies have been made of the nuclear magnetic resonance spectra of several allylic Grignard reagents. The Grignard reagent prepared from $\gamma, \gamma$-dimethylallyl bromide appears best formulated as an equilibrium mixture of $\gamma, \gamma$-dimethylallylmagnesium bromide and $\alpha, \alpha$-dimethylallylmagnesium bromide, in which the former is the major component. The rate of interconversion of the allylic isomers is rapid on the n.m.r. time scale at room temperature, but slow at $-40^{\circ}$.

The ability of allylic Grignard reagents to yield products derived from the starting halide and the corresponding allylic isomer has stimulated extensive investigation into the constitution of this class of organometallic compound. Several general reviews give details of these investigations : 1,2 only a few particulars which are pertinent to the work presented in this paper will be mentioned here.

A particularly troublesome question in attempts to explain the reactions of allylic Grignard reagents has been that of the existence and degree of equilibrium between allylic isomers of the type shown in eqn. (1):

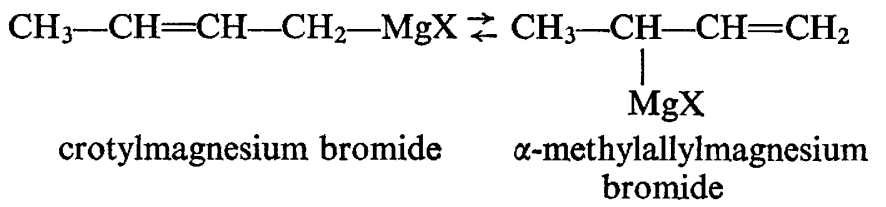

Young and co-workers were able to show that the proportions of isomeric butenes obtained on hydrolysis of Grignard reagents prepared from various mixtures of the isomeric crotyl- and $\alpha$-methylallyl bromide were completely independent of composition : 3, 4 a similar result was obtained in the reduction of the halides to butenes in the presence of finely divided metals. 5-7 These data were originally interpreted as evidence for a rapidly equilibrating mixture of butenyl organometallic compounds, in which both crotyl- and $\alpha$-methylallyl isomers existed to approximately the extent corresponding to the composition of the respective butenes formed by hydrolysis. However, in later studies, the butenyl Grignard reagent was found to react with carbon dioxide 8 and phenyl isocyanate ${ }^{9}$ to yield almost exclusively $\alpha$-methylallyl derivatives (eqn. (2)) :

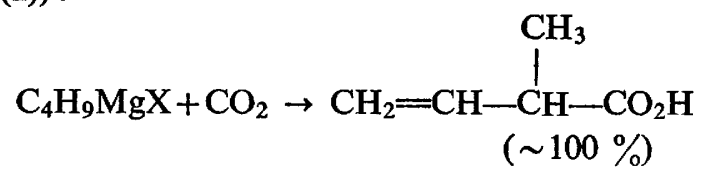

These and similar results using a variety of aldehydes and ketones, 9 -11 $\alpha, \beta$-unsaturated carbonyl compounds, 9 and allylic halides 12 were interpreted as rendering the

* supported in part by the Office of Naval Research.

† Contribution no. 2847. 
hypothesis of a rapidly equilibrating mixture of Grignard isomers less satisfactory than an alternative formulation in which the Grignard reagent is taken to be almost exclusively the crotyl isomer.11,13

In recent years, the problem of constitution of allylic Grignard reagents has been further complicated by discovery of a remarkable series of allyl-transition metal compounds, whose structures seem well established as $\pi$-complexes of the metal with the allyl moiety. ${ }^{14-16}$ The possibility that allylic Grignard reagents might be similar complexes of magnesium with the allyl residue had been suggested earlier 11 but offered no special advantage in interpreting the chemical evidence then available.

Despite the large amount of pertinent chemical evidence, the problem of the composition of allylic Grignard reagents could not be considered solved; indeed, Kharasch ${ }^{1}$ has asserted that the problem is incapable of purely chemical solution. The work reported in this paper was initiated in the belief that nuclear magnetic resonance (n.m.r.) spectroscopy offered an especially appropriate, non-destructive physical method with which to investigate the constitution of simple allylic Grignard reagents in solution.

\section{EXPERIMENTAL}

The allylic Grignard reagents were prepared in the cyclic reactor shown in fig. 1 through the reaction of a dilute solution of the corresponding halides in diethyl ether with a column of amalgamated magnesium turnings (prepared by treating the magnesium in situ with an equal weight of mercuric bromide dissolved in ether, followed by thorough washing with ether). Amalgamation was found to reduce materially the yield of coupling products formed in the reaction. The magnesium used in these experiments was turned from a bar of very pure resublimed metal; use of ordinary magnesium invariably gave samples whose n.m.r. spectra appeared to be broadened by paramagnetic impurities.

The preparations normally were carried out with 0.01 mole of halide. The rotary selector of the cyclic reactor was initially positioned away from the flask with the sinteredglass disc. After $0.015 \mathrm{~g}$ atom of magnesium had been amalgamated, activated with ethylene dibromide, 17 and washed with ether, the flask containing the washings was replaced with a flask containing fresh ether, and the ether heated to reflux. The allylic bromide was then added slowly to the stream of condensing ether, and the top pieces of magnesium were punctured with the tungsten needle to initiate reaction. After an initial induction period, a vigorous reaction occurred; when this had subsided, the flow from the column was directed into the second terminal flask. The reaction was allowed to proceed at such a rate that slight ebullition was always apparent in the column. When the addition was complete, the solution in the terminal flask was filtered through the sintered-glass frit and concentrated in a stream of dry nitrogen in the round-bottomed flask equipped with n.m.r. tubes as sidearms. The concentrated solution was decanted into the n.m.r. tubes; these were broken off, charged with tetramethylsilane, sealed, and centrifuged to remove suspended solids.

With this apparatus, it was possible to prepare allylmagnesium bromide * and butenylmagnesium bromide essentially free of coupling products. It proved impossible to prepare $\gamma, \gamma$-dimethylallylmagnesium bromide by this method without serious contamination by coupling products; however, the coupling products could be removed from saturated ethereal solutions of this Grignard reagent by extraction of the solution three times with an equal volume of dry iso-octane (or similar saturated aliphatic hydrocarbon). These extractions were conveniently carried out directly in the n.m.r. tube. After addition of the iso-octane, the tube was stoppered and shaken vigorously. The layers were separated by centrifugation, and the upper (iso-octane) layer removed with a dropper. After the final extraction, the thick residue was diluted with approximately four times its volume of fresh ether, mixed, and centrifuged.

* In this paper, the solvated organometallic compound prepared from allyl bromide and magnesium in ether will be called allylmagnesium bromide, although investigations into the constitution of Grignard reagents indicate that this representation is at best incomplete.18, 19 
N.m.r. spectra were taken using solutions approximately $10 \%$ Grignard reagent; spectra of more concentrated solutions displayed pronounced viscous broadening, particularly at low temperatures. The Grignard reagents appeared to be indefinitely stable; on standing a slow deposition of crystals (presumably magnesium bromide) frequently occurred in the sample tubes, but the spectra did not change.

Spectra were taken at $60 \mathrm{Mc} / \mathrm{sec}$ on a Varian model V-4300B spectrometer equipped with a Superstabilizer. Chemical shifts were measured by standard audio sideband techniques 20 using a Hewlett-Packard Model 200AB audio oscillator and Model $521 \mathrm{C}$ frequency counter. The low-temperature apparatus has been described previously ;21 temperatures in the probe were measured using a calibrated copper-constantan thermocouple together with a Leeds and Northrup precision potentiometer.

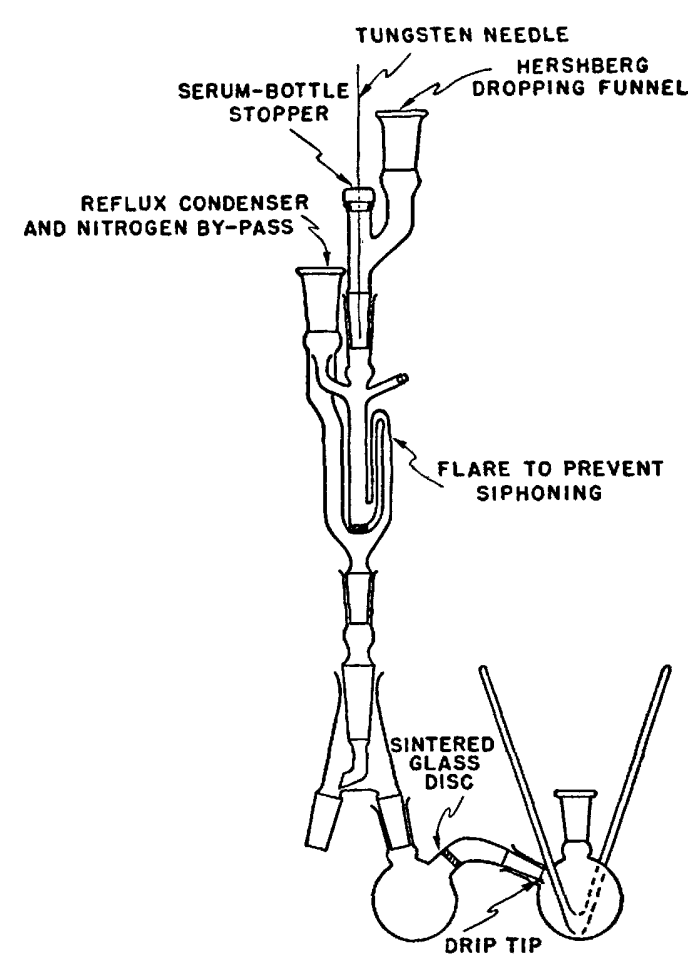

FIG. 1.-Cyclic reactor and accessory apparatus used in the preparation of the allylic Grignard reagents.
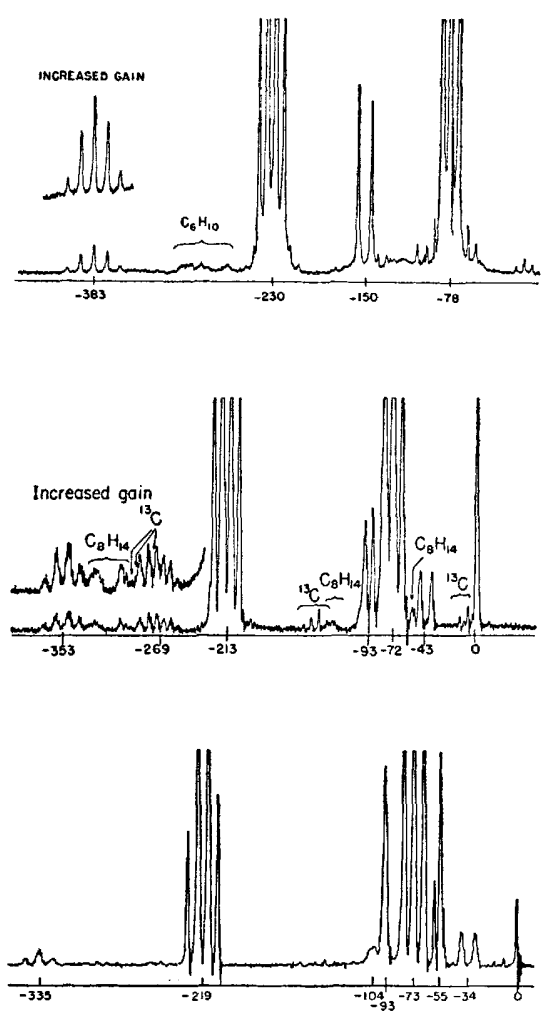

FIG. 2.-Nuclear magnetic resonance spectra of allylmagnesium bromide (top) butenylmagnesium bromide (middle) and $\gamma, \gamma$-dimethylallylmagnesium bromide (bottom) in diethyl ether at $33^{\circ}$ and $60 \mathrm{Mc} / \mathrm{sec}$. The intense quartet and triplet in each spectrum are the resonances of the diethyl ether $\mathrm{CH}_{2}$ and $\mathrm{CH}_{3}$. The complex of lines at $-55 \mathrm{c} / \mathrm{sec}$ in the bottom spectrum is due to iso-octane. Chemical shifts are in $\mathrm{c} / \mathrm{sec}$ from tetramethylsilane ( $0 \mathrm{Mc} / \mathrm{sec})$ as external (top) or internal (middle and bottom) standard.

\section{DISCUSSION}

Allylmagnesium bromide shows an $\mathrm{AX}_{4}$-type 21 n.m.r. spectrum 22 (fig. 2); that is, the four $\alpha$ and $\gamma$ protons are magnetically equivalent with respect to the $\beta$ proton 
and coupled to it with $J=12 \mathrm{c} / \mathrm{sec}$. This spectrum can be accounted for by postulating that the Grignard reagent is either a rapidly equilibrating $\left(t_{\mathrm{t}} \ll 0.001 \mathrm{sec}\right)$ mixture of classical structures (I) or a bridged structure with magnetically equivalent protons (II). The same interpretation is required for $\beta$-methylallylmagnesium bromide whose spectrum shows a methyl group and only one other kind of proton.<smiles>C=CCCCCC(C)Br</smiles>

II

The n.m.r. spectrum of butenylmagnesium bromide (fig. 2) shows the spinsplitting and pattern of chemical shifts consistent with crotylmagnesium bromide. This spectrum indicates either that the substance exists exclusively as crotylmagnesium bromide or that the position of equilibrium of a rapidly equilibrating mixture of isomers must be so far toward the primary isomer that the average spectrum is essentially that of the primary isomer. In this regard, it is interesting that no changes of more than $1 \mathrm{c} / \mathrm{sec}$ occur in the proton chemical shifts of the butenyl Grignard reagent over a temperature range of $50^{\circ}$. On the basis of reasonable assignments for the chemical shifts of the protons of $\alpha$-methylallylmagnesium bromide, this means either that $\Delta H$ is virtually zero for the equilibrium between the tautomers or that the primary form is present to the extent of $99 \%$ or more. Neither magnesium bromide nor the solvent appears to play any important specific role in these systems because the same kind of behaviour is noted for solutions of both diallylmagnesium and dicrotylmagnesium in dioxane.

It is particularly interesting that the proton spectrum 24 of an ethereal solution of the Grignard reagent from $\gamma, \gamma$-dimethylallyl bromide is, with one exception, just what would be expected for $\gamma, \gamma$-dimethylallylmagnesium bromide (III)-a triplet in the vinyl proton region, a high field doublet, and a sharp singlet at slightly lower field than the methyl quartet of the solvent; these resonances can be assigned respectively to the single $\beta$ proton, the two $\alpha$ protons and the six methyl protons of $\gamma, \gamma$-dimethylallylmagnesium bromide. The exception is that at room temperature, there is but a single methyl resonance (fig. 2). This despite the fact that the methyl groups are expected to have at least slightly different chemical shifts as<smiles>CC(C)=CCC(C)Br</smiles>

III<smiles>C=CC(C)(C)Br</smiles>

IV

befits their geometrical relationships (cis and trans) to the vinyl hydrogen. However, unlike allylmagnesium bromide and butenylmagnesium bromide, 25 whose spectra are independent of temperature from $+33^{\circ}$ to $-80^{\circ}$, the methyl proton spectrum of $\gamma, \gamma$-dimethylallylmagnesium bromide in diethyl ether possesses a revealing temperature dependence. Thus on lowering the temperature, the methyl proton resonance broadens and then splits symmetrically into two equal components. Neither the high field doublet nor the vinyl triplet change their form or position. 
This temperature dependence appears to exclude a symmetrical structure analogous to (II) for this Grignard reagent. The methyl groups in such a structure would be static; a change in temperature would be expected to leave the spectrum unaffected. Hence, we believe that $\gamma, \gamma$-dimethylallylmagnesium bromide is best considered to be a rapidly equilibrating mixture of primary and tertiary isomers [(III) and (IV)]. The equivalence of the methyl groups at room temperature is seen to be due to the incursion of (IV), in which there is more or less free rotation about the central $\mathrm{C}-\mathrm{C}$ bond. As with the butenyl Grignard reagent, the temperature independence of the chemical shift of the methylene protons of this Grignard

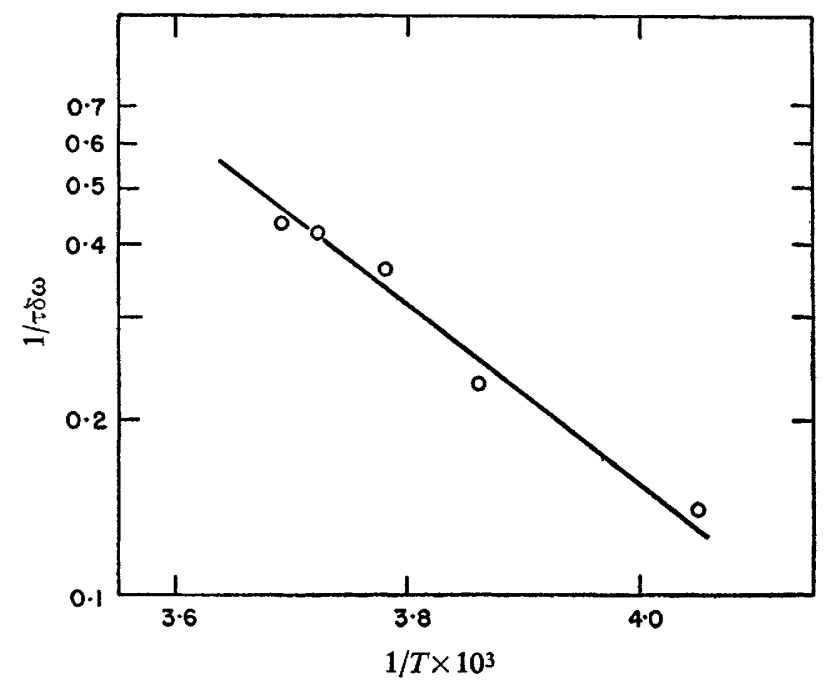

FIG. 3.-Plot of $1 / \tau \delta \omega$ as a function of $1 / T$ for the methyl proton resonances of $\gamma, \gamma$-dimethylallylmagnesium bromide in diethyl ether.

reagent is of particular significance. Since interconversion between allylic isomers is rapid, the chemical shift of these protons is an average of the chemical shifts of the methylene protons of the primary and tertiary isomers, weighted according to their relative concentrations. ${ }^{26}$ If appreciable amounts (greater than $1 \%$ ) of the less stable tertiary isomer exists in equilibrium with the primary, a decrease in temperature would be expected to shift the methylene resonance to higher fields, corresponding to an increase in the more stable isomer. No temperature dependence was observed; hence this Grignard reagent, like butenylmagnesium bromide, must exist almost entirely as the primary isomer.

A plot (fig. 3) of $\log _{10}(1 / \tau \delta \omega)$ against $1 / T^{27}$ yields $\Delta H^{*}=7 \pm 3 \mathrm{kcal} / \mathrm{mole}$ and $A^{*}=10^{3}-10^{4} \mathrm{sec}^{-1}$ for the process leading to interchange of the cis- and transmethyl groups of $\gamma, \gamma$-dimethylallyl-magnesium bromide. Here, $\tau=1 / k_{1}+k_{-1}$, and $\delta \omega$ is the separation between the components of the methyl proton resonance, corrected for overlap.

The position of equilibria between primary and secondary or between primary and tertiary isomers of allylic Grignard reagents is expected to favour strongly the primary forms on three counts. First, a double bond on the end of a chain is less stable by $2-3 \mathrm{kcal}$ than one in the centre of a chain. Secondly, the inductive effects of alkyl groups are such to create a more favourable environment for attachment of magnesium on primary carbons than on secondary or tertiary carbons. Thirdly, 
complex formation between ether and magnesium makes for a bulky substituent group, which will experience the minimum of steric hindrance when connected to a primary carbon.

The essentially exclusive formation of re-arrangement products from allylic Grignard reagents and carbonyl compounds is most readily accounted for in the following way. Initial co-ordination between carbonyl compound and magnesium effectively freezes the "end-for-end" equilibration of the allylic group and is followed by a cyclic addition process with rearrangement:<smiles>[X][M]OC([R])([R])CCC</smiles><smiles>[Y4]COC([R])([R])C(C)C</smiles>

When reaction with rearrangement is completely precluded by steric hindrance, as with di-t-butylketone, ${ }^{13}$ then reaction occurs by the normal path to introduce the allylic group attached at the primary carbon.

1 Kharasch and Reinmuth, Grignard Reactions of Nonmetallic Substances, (Prentice-Hall, Inc. N.Y., 1954), chap. XVII.

2 De Wolfe and Young, Chem. Rev., 1956, 56, 753.

3 Young, Prater and Winstein, J. Amer. Chem. Soc., 1933, 55, 4908.

4 Young, Winstein and Prater, J. Amer. Chem. Soc., 1936, 58, 289.

5 Young and Eisner, J. Amer. Chem. Soc., 1941, 63, 2113.

6 Young and Winstein, J. Amer. Chem. Soc., 1936, 58, 441.

7 Young, Kaufmann, Loshokoff and Pressman, J. Amer. Chem. Soc., 1938, 60, 900.

${ }^{8}$ Lane, Roberts and Young, J. Amer. Chem. Soc., 1944, 66, 543.

9 Young and Roberts, J. Amer. Chem. Soc., 1946, 68, 649.

10 Young and Roberts, J. Amer. Chem. Soc., 1944, 66, 2131 ; 1945, 67, 145, 319.

11 Young and Roberts, J. Amer. Chem. Soc., 1946, 68, 1472.

12 Young, Roberts and Wax, J. Amer. Chem. Soc., 1945, 67, 841.

13 Wilson, Roberts and Young, J. Amer. Chem. Soc., 1950, 72, 215, 218.

14 See Hoehn, Cripps, Muetterties, Howk, J. Amer. Chem. Soc., 1961, 83, 1601.

${ }^{15}$ Dehn and Chien, J. Amer. Chem. Soc., 1960, 82, 4429.

16 Rowe, Proc. Chem. Soc., 1962, 66.

17 Pearson, Cowan and Beckler, J. Org. Chem., 1954, 24, 505.

18 Dessy, Handler, Wotiz and Hollingsworth, J. Amer. Chem. Soc., 1957, 79, 3476.

19 Dessy and Handler, J. Amer. Chem. Soc., 1959, 80, 5824.

20 Arnold and Packard, J. Chem. Physics, 1951, 19, 507.

21 Shoolery and Roberts, Rev. Sci. Instr., 1957, 28, 61.

22 Pople, Schneider and Bernstein, High-Resolution Nuclear Magnetic Resonance, (McGraw-Hill, N.Y., 1959), chap. 6.

23 Nordlander and Roberts, J. Amer. Chem. Soc., 1959, 81, 1769.

24 Whitesides, Nordlander and Roberts, J. Amer. Chem. Soc., 1962, 84, 2010.

25 Nordlander, Young and Roberts, J. Amer. Chem. Soc., 1961, 83, 494.

26 ref. (22), chap. 10.

27 Gutowsky and Holm, J. Chem. Physics, 1959, 25, 1228. 